\title{
THE ATTITUDES OF NURSES TOWARDS MENTALLY ILL PEOPLE IN A GENERAL HOSPITAL SETTING IN DURBAN
}

\author{
TR MAVUNDLA AND LR UYS
}

\begin{abstract}
A quantitative survey was undertaken to determine the attitudes of nurses towards mentally ill people at King Edward VIII Hospital, large academic hospital in Durban. Data were collected by a questionnaire intended to measure attitudes according to cognitive, affective and behavioral components in a sample of 100 black nurses. The results of this study were analyzed through a statistical software package, the statgraphic version 5.

The basic trend reflected in the findings found that nurses in general hospitals (90\%) held negative attitudes towards mentally ill people and there were few nurses with positive attitudes. There were significant differences among the three different categories of nurses in only five of the items. Further data analysis was done by stepwise regression showing that religious affiliation and relationship to mentally ill people correlated significantly with the total attitude score.
\end{abstract}

\section{INTRODUCTION}

Development of general hospital psychiatry created difficulties for staff members. MacDonald (1988) found that staff in medical and surgical settings often share to a surprising degree the fears and irrational expectations of the laity, leading to the development of ambivalent attitudes towards both mental iliness and staff in the psychiatric department. Individual staff members are dealt with as exceptions but various comments that are made such as: "You are the only sane psychiatrist I know ", demonstrate that the exception truly proves the rule.

The needs of mentally ill people may not be adequately met in these settings. If the patient admitted to any general hospital department was once hospitalised for mental illness, his present problems may not be seriously considered even if his mental illness is well controlled. Instead of being fully assessed physically, a psychiatrist may be called to do a mental status examination, often resulting in mentally ill people being poorly treated for general health concerns(Personal experience).

Nurses in the psychiatric department, too, experience stress when nursing patients with a dual diagnosis of physical and mental illness, since they feel the acute physical problem should lead to admission to a medical or surgical unit. It is the same with nurses in medical-surgical settings who are unhappy when nursing dual diagnosis patients since they feel these patients should always be admitted to the psychiatric unit. Medical-surgical nurses often express their feelings in statements like: "We will not be held responsible if this patient jumps out of that window and dies" (MacDonald, 1988). Such beliefs not only affect the patient concerned, but also the relationship between staff of different departments who may end up in dispute.

\section{BACKGROUND OF PROBLEM}

There is a relationship between the knowledge people have about mental illness and attitudes towards it. Several studies report a change in attitudes after introduction of psychiatric concepts in the nursing curricula (Jaffe, Maoz and Avram, 1979; Olade, 1983; Clarke, 1989; Wahl and Lefkowits, 1989; Chinnayya et al, 1990).

In South Africa a comprehensive basic nursing programme was introduced in 1986 in which psychiatric nursing was included and it may be expected that such comprehensive training would improve attitudes towards the nursing of psychiatric patients.

Nevertheless, many nurses in the clinical setting still have no experience of psychiatric nursing. Their attitudes may still be negative, and since they mostly are the more senior group in terms of years of experience, these negative attitudes may be dominant. The researcher, therefore, believes it important to describe the attitudes of nurses in a general hospital towards mentally ill persons.

\section{RESEARCH OBJECTIVES}

The objectives of the study were:

* To investigate attitudes held by nurses in a general hospital setting towards mentally ill people,
* To identify factors influencing these attitudes and,

* To measure the frequency of contact general hospital nurses had with mentally ill people.

\section{DEFINITION OF TERMS}

Attitude: It is a way of feeling, thinking and behaving (Homby, 1984). In this study, this definition applies to attitudes displayed by nurses towards mentally ill people.

Dual diagnosis: The presence of both a physical and a mental illness in a patient who presents herself for treatment in a general hospital setting.

\section{THEORETICAL FRAMEWORK}

The study was based on the theory of reasoned action proposed by Azjen and Fishbein(1980), which provides a good basis for measuring attitudes. This theory is based on the assumption that human beings are rational and make systematic use of information available to them; people therefore consider the implications of their actions before they decide to engage in given behaviour. A person's intention to perform a behaviour is viewed as the immediate determinant of the action, and a person's intention is seen as a function of two basic determinants, one personal and the other reflecting social influence. The personal factor is the individual's positive or negative evaluation of performing the behaviour; this is termed attitude toward the behaviour. The second determinant of intention is the person's perception of the social pressure put on him to perform or not perform the behaviour in question. Since it deals with perceived prescription, this factor is termed behavioral belief.

Subjective norms are also a function of beliefs, but beliefs of a different kind, namely the person's belief that specific individuals or groups think he/she should not perform the behaviour. These beliefs mderlying a person's subjective norm are termed normative beliefs. The behaviour in question in this study was the nursing care of the mentally ill people in general hospital settings. 


\section{LITERATURE REVIEW}

General Public Attitudes Towards Mental Ilness

Various studies have been conducted worldwide addressing the issues of attitudes and stigma attached to mentally ill people. In South Africa a survey was conducted by Uys et al (1986) among urban black population of Mangaung, which explored their views on life, illness behaviour, etiology and treatment. In this survey special attention was given to mental illness and results indicated that black families had negative attitudes towards mentally ill people. They reported that they feared mentally ill people and did not believe what they said. A strong trend towards a Western and Christian view of these matters was shown.

In the United States of America, Taylor, Dear and Hall (1979), examined the relationship between attitudes towards the mentally ill and reaction to potential and existing facility locations with data collected in a questionnaire survey of 1090 cases. Attitudes in this study were measured in terms of four scales: authoritarianism, benevolence, social restrictiveness, and community mental health ideology. Results showed a strong relationship supporting the primary importance of attitudes towards the mentally ill as a basis for explaining and predicting public reaction to the community mental health facilities. Attitudes towards facilities were shown to be more favourable than commonly supposed, leading to the conclusion that opposition is limited to a vocal minority whose views are not representative of the whole community.

On the other hand, public attitudes towards the mentally ill were examined using questionnaire data from 108 members of the population of two large British cities. (Niradzk and Cochrane 1985). Four hypotheses were confirmed:- that public attitudes towards mental illness were more rejecting than accepting; that social rejection increases with severity of behavioral disturbances; that the availability of a non-deviant alternative label decreases rejection; and that the label of mental illness increases rejection independently of behaviour indicative of mental illness. However, the fifth hypothesis was only partially confirmed in that rejection is related to respondent's age, but not occupational status.

\section{THE INFLUENCE OF TRAINING ON ATTITUDES}

An early study was done among 69 student nurses in Israel during 1979 (Jaffe, Moaze \& Avram; 1979). The following factors were assessed before and after psychiatric affiliation in two kinds of hospitals:- stereotyped image, authoritarianism, social restrictiveness, benevolence, mental hygiene and interpersonal aetiology. The findings demonstrated that (i) classroom instruction is ineffective as an agent of change; and (ii) that practical experience involving personal confrontation which contradicts the stereotyped image of the mental patients and inculcates positive attitudes towards them, results in more human, accepting and liberal attitudes.

Glade (1983), used the same instrument, but looked at a programme integrating mental health concepts into a post-basic nursing programme with two classes of students who had minimal psychiatric preparation in their diploma programme. She studied these students as they progressed from first to third year of study. Using the same questionnaire, she assessed if there were any changes in the six attitudinal factors measured above. The results showed changes only in terms of their authoritarianism and social restrictiveness. The comparative lack of success in attitudinal change may be related to the greater rigidity of the more mature students usually found in post-basic programmes or to the integrated character of this programme.

Clarke(1989), looked at attitudes towards treatment and compared attitudes of student psychiatric nurses towards treatment at different points of their training. He reported that the groups differed significantly in their attitudes towards treatment, with the first year group being significantly more liberal, having a more positive attitude towards physical treatment than the second and the third year groups. This may mean that nurses become negative as their experience of health services increase.

Specificity may play an important role in changing attitudes towards mentally ill patients. This is demonstrated in a study in which 150 primary health care paramedical were trained specifically in mental health care. Attitudes were assessed before and after training. The trainees showed a significant change in attitudes in a positive direction. Their baseline attitudes were not related to age, level of education or duration of professional service. Those with low baseline attitudes score registered a significantly higher gain (Chinnayya, et al; 1990)

The success of changing attitudes may lie in the method utilised. Landeen, Byrne and Brown (1992) evaluated the impact of joumal keeping on student nurses' attitudes towards psychiatric clients and self-awareness in relation to others. Third year nursing students completing a psychiatric rotation kept journals which were used to reflect on thoughts and feelings engendered by their clinical experience. In this study two control groups were used:-one completing a psychiatric rotation without keeping journals; and the second, completing a medical - surgical rotation. The findings supported the use of journals to assist students in exploring and changing their attitudes, but not necessarily in changing their interpersonal style.

On the other hand, level of eduction may improve or sour attitudes towards mental illness. Mack and Tosan (1980) investigated the effects of education on attitudes towards mental illness. University undergraduates with relatively high levels of education were compared with market traders with a much lower level of education.
The respondents were asked 40 questions measuring attitudes towards mental illness. Results revealed significant differences in attitudes between educational categories.

\section{STUDY DESIGN}

A descriptive study in the form of a survey was conducted by the researcher at King Edward VIII hospital in October 1993. The population comprised all nurses working in this large urban general academic hospital. The type of sampling procedure utilised was systematic, a method of probability sampling which gives every element in the population a known chance of being included in the sample. In this study, inclusion was done by taking the staff change list for October and selecting every tenth nurse on the list.

A sample of 100 subjects was drawn from three categories of nurses, 40 of these were registered nurses, 30 enrolled nurses and 30 enrolled nursing assistants. The reason for including all the categories of nurses was the fact that they all have an influence in the care of the mentally ill in general settings.

All subjects were approached during tea and lunch breaks and questionnaires were given to them to complete. Each questionnaire was accompanied by a covering letter that assured all the participants about their rights. The rating scale was designed to be simple, to enable all the subjects to understand it.

The tool consisted of a rating scale developed from four rating scales used in similar studies (Taylor et al, 1979; Mack and Tosan, 1980; Hiday, 1983; Chinnayya et al, 1990).

A new tool was constructed as the above-mentioned tools did not fit in the theoretical framework for this study. In Taylor's instrument only affective statements were taken. Mack and Tosan's instrument only addressed ethnic factors. Hiday's instrument was not selected because it was not specific to attitudes affecting mentally ill people, but it included statements about mental hospitals and psychiatrists. In Chinnayya's instrument there were generalized statements which were not suitable for use in a study that specifically was assessing attitudes towards mentally ill people.

To establish validity of the tool, the $\mathrm{ABC}$ model of measuring attitudes was also used in this study. This model is based on the assumption that, for the tool which measures attitudes to be valid, the affective, behavioral and the cognitive components should be well represented.

To establish validity, five experienced nurses and one researcher were asked to examine whether or not the scale seemed to be measuring that which it was intended to measure. It was found to correspond with the categories of affect, cognitive and behaviour and the panel agreed that the relevant items from previous instruments were included. 


\begin{tabular}{|ccccccc|}
\hline \multicolumn{7}{c}{ TABLE 1 : WORKING AREA OF 100 RESPONDENTS } \\
Casualty & Medicine & Surgery & Maternity & Paediatrics & Other \\
11 & 23 & 13 & 16 & 12 & 23 \\
\hline \multicolumn{7}{c}{ TABLE 2: FREQUENCY OF CONTACT WITH MENTALLY ILL PEOPLE } \\
Eaily & 3 Days & Woekly & Monthly & Yearly & Other & Total \\
36 & 7 & 15 & 21 & 11 & 10 & 100 \\
\hline
\end{tabular}

The questionnaire was pretested on twenty nurses who were not included in the study, to ensure that instructions and items were clear. They had no difficulty in understanding either the instructions or the items.

Permission to conduct the study was obtained from relevant authorities. The study was also approved by the Ethics Committee of the University of Natal's Faculty of Social Sciences and the Natal Provincial Administration Head Office. Data were analyzed by means of a computerised statistical software package : Statgraphic version 5 .

\section{RESULTS}

\section{Sample Characteristics}

Of the 100 respondents, 40 were registered nurses, 30 were enrolled nurses and the other 30 were enrolled nursing assistants. There were 25 males and 75 females represented.

The age of respondents varied from 20 to 61 years old. The smallest group was that between the ages of 51 to 60 . Only one subject fell between the of 61 years and over.

Most respondents (51\%) fell within the mainstream Protestant churches (Lutheran, Methodist, and Anglican), while the Roman Catholic church was also well represented (23\%). One respondent was Zionist, one was Muslim and two fell into unspecified religious groups.

The highest school standard passed by the respondents in the main was standard ten or Matriculation (84\%) whilst $12 \%$ of respondents had Standard 8 and 4 respondents had attained Standard 9.

The ratio of registered nurses to other categories in the nursing profession in South Africa is about 1:1. In this study, the ratio was 1:06.

Of the 100 respondents, only 14 revealed that they had a relative who was mentally ill. Seven of these had a brother who was mentally ill, 3 had a niece or a nephew with mental illness, 1 had a sister, and another one had an uncle affected. One respondent did not specify the relationship between him and his relative.

Table 1 shows the even work distribution of respondents through all hospital departments
Most of the respondents (36\%) indicated that they meet mentally ill people every day. Table 2 shows frequency of contact with the mentally ill.
ATTITUDES TOWARDS THE MENTALLY ILL PERSON

Cognitive beliefs about nursing mentally ill people are shown in Table 3 . The responses to items 1 to 11 were totalled after scores had been corrected for negative items. Since the score of 3 on each item indicated uncertainty, only scores of 4 or 5 on an item could be regarded as positive. Only total scores of 44 and above therefore were seen as positive cognitive attitudes. With an average of 28,51 and $56 \%$ of the respondents in the score range of below 30 , the cognitive component of their attitudes was mainly negative. The attitudes of only $2 \%$ could be classified as clearly positive.

\begin{tabular}{|c|c|c|c|c|c|}
\hline \multicolumn{6}{|c|}{ TABLE 3 : FREQUENCY COUNTS FOR COGNITIVE BELIEFS } \\
\hline COGNITIVE STATEMENTS & SN & NE & UC & PO & SP \\
\hline Most mentelly ill people are dangerous & 31 & 29 & 10 & 23 & 7 \\
\hline \multicolumn{6}{|l|}{ It is easy to recognise someone who one } \\
\hline \multicolumn{6}{|l|}{ We cannot expect to understand the bizarre } \\
\hline \multicolumn{6}{|l|}{ Most mentally ill do not have the ability to } \\
\hline Most people have mental / emotional & 31 & 48 & 11 & 10 & 0 \\
\hline Most mentally ill people don't care how they look. & 29 & 31 & 4 & 30 & 6 \\
\hline Mental illness is nothing to be ashamed of. & 28 & 37 & 10 & 15 & 10 \\
\hline $\begin{array}{l}\text { Mentally ill people are ruled by their emotions, } \\
\text { normal people by their reasons }\end{array}$ & 25 & 50 & 10 & 9 & 6 \\
\hline $\begin{array}{l}\text { A mentally ill person is in no position to make } \\
\text { decisions about everyday living problems. }\end{array}$ & 22 & 28 & 12 & 27 & 11 \\
\hline Mentally ill people are not intelligent & 8 & 10 & 11 & 39 & 32 \\
\hline \multicolumn{6}{|l|}{ There is something about the mentally ill that } \\
\hline \multicolumn{6}{|c|}{$\mathrm{SN}=$ More Negative, NE $=$ Negative, $U C=$ Uncertain, $P O=$ Positive, $S P=$ More Positive. } \\
\hline $\begin{array}{ll}\text { Mean }=28.51 & \text { Possible total }=55 \\
\text { Standard deviation }=6.522 & \text { Positive range }=44-55 \\
\text { Median }: 28 & \end{array}$ & & & & & \\
\hline
\end{tabular}

\begin{tabular}{|c|c|c|c|c|c|}
\hline \multicolumn{6}{|c|}{ TABLE 4 : FREQUENCY COUNTS FOR BEHAVORAL BELIEFS $(N=100)$} \\
\hline BEHAVIORAL BELIEFS \& SUBJECTIVE NORM & SN & NE & UC & PO & SP \\
\hline $\begin{array}{l}\text { Transferring mentally ill people to the department } \\
\text { of psychiatry is rourtine to us nurses }\end{array}$ & 17 & 29 & 10 & 36 & 8 \\
\hline $\begin{array}{l}\text { Most of us nurses believe that if you work in a } \\
\text { psychiatric department you end up mentally disturbed }\end{array}$ & 18 & 23 & 17 & 14 & 28 \\
\hline $\begin{array}{l}\text { In our hospital we ty and adopt a tolerant } \\
\text { attitude towards mentally ill people. }\end{array}$ & 22 & 53 & 8 & 15 & 2 \\
\hline $\begin{array}{l}\text { We believe that as soon as the person becomes } \\
\text { mentally ill, he/she should be removed from } \\
\text { the community }\end{array}$ & 12 & 26 & 8 & 23 & 31 \\
\hline $\begin{array}{l}\text { Most of my friends and l avoid mentally ill } \\
\text { people to prevent being hurt }\end{array}$ & 15 & 30 & 7 & 28 & 20 \\
\hline $\begin{array}{l}\text { It is our rule that the best way to handle the } \\
\text { mentally ill is to keep him/her behind locked } \\
\text { doors or restrained }\end{array}$ & 10 & 14 & 11 & 31 & 34 \\
\hline $\begin{array}{l}\text { The health professionals believe that the best } \\
\text { therapy for mamy mental patients is to be part } \\
\text { of the normal community }\end{array}$ & 37 & 33 & 9 & 11 & 10 \\
\hline \multicolumn{6}{|c|}{$\mathrm{SN}=$ More Negative, NE $=$ Negative, $\mathrm{UC}=$ Uncertain $\mathrm{PO}=$ Positive, $\mathrm{SP}=$ More Positive } \\
\hline $\begin{array}{l}\text { Mean }=20.54 \\
\text { Standard deviation }=5.526 \\
\text { Median }=20.5\end{array}$ & & & & & \\
\hline
\end{tabular}


The standard deviation in this category was low meaning that most respondents were close to the average. The frequency counts for cognitive items towards the mentally ill indicated that they were more negative on questions testing stereotypes. This clearly indicated that under normal circumstances, mentally ill people are subject to stigmatization. Cognitively they are not classified as important members of our society.

Behavioral beliefs about nursing mentally ill people and the subjective norm of respondents are displayed in Table 4 . This section consisted of the scores of items 12 to 18 ; attitudes towards mentally ill people were very negative with only $5 \%$ respondents within the positive range.

Frequency count scores of behaviour towards the mentally ill indicated that mentally ill people are not yet accepted in general settings.

Affective statements about nursing mentally ill people are displayed in Table 3.

The positive range in affective statements was between 20 to 25 with the average of 14.5 and $56 \%$ of the respondents in the range below 16 . From these results, their affective scores were mainly negative. Affective counts also indicated that nurses did not have positive feelings for mentally ill people and that they do not feel responsibility towards mentally ill people.

\section{The Total Attitude Score}

The total positive attitude score had a range of 92 - 115. The average was found to be 63.55 . This score included totals of three factors which were measured as cognitive, behavioral and affective items.

\section{FACTORS FOUND TO INFLUENCE ATTITUDES}

\section{Nursing education}

The results in this section of the study indicated that registered nurses were more positive when compared with other categories of nurses. Enrolled nurses also showed more positive responses than nursing assistants.

\section{TABLE 7 : ITEMS ON WHICH DIFFERENT CATEGORIES OF NURSES GAVE SIGNIFICANTLY DIFFERENT ANSWERS}

Most mentally ill people are dangerous

Most mentally ill people don't care how they look

$\star 0.001075$

Transferring mentally ill people to the department of

psychiatry is routine to us nurses

It is a rule that the best way to handle the mentally ill is to

keep him/her behind locked doors or restrained

The mentally ill should be held responsible for

what he/she has done wrong
2. Religious affiliation and the relationship to

Through stepwise regression it was found that religious affiliation and the relationship to mentally ill people contributed about $13 \%$ to the Attitudes towards the mentally ill people were mainly negative. Religious affiliation, the relationship to mentally ill people and nursing education proved to be significant factors

\section{DISCUSSION, CONCLUSION AND}

In general there seem to be few nurses who had general hospital settings. Most nurses were Although there were few significant differences found in items among different categories of nurses, results indicated that most attitudes mentally ill people are not due to demographic factors like age, rank of respondent and marital status.

\begin{tabular}{c} 
SCORES \\
$25-44$ \\
$45-63$ \\
$64-81$ \\
$82-100$ \\
115 \\
\hline
\end{tabular}

PERCENTAGE
6
39
50
5
100

The differences found among nurses of different categories may be influenced by the level of education. These findings correspond with those of Mack and Tosan (1980), who reported that with higher levels of education there will be better attitudes. It also appeared that religious affiliation and the relationship with mentally ill people had a significant relationship with attitude scores. This may be attributed to the fact that most religions expect more caring attitudes from adherents. Most people who are relatives of mentally ill people may have more knowledge and understanding and therefore be more positive towards mentally ill people.

In terms of the theory of reasoned action the respondents hold negative personal attinudes and negative subjective norms about nursing mentally ill people in general hospital settings. The data were consistent with the predicted relationships among the model components. The respondents strong intention not to take care of mentally people in general settings was based on their attitudes towards performing this behaviour and their perception (subjective norm) that significant others would not approve.

\section{LIMITATION OF THE STUDY}

Since only black nurses in one hospital were involved in the study the findings could not be generalised throughout South Africa.

\section{RECOMMENDATIONS}

Training, especially that for enrolled nurses who are studying towards the bridging course, enrolled nurses training and enrolled nursing assistants training should have a module in psychiatric nursing. The content of that module should not be nursing care of psychiatric conditions, but it should address the myth, irrational expectations and irrational beliefs 
about mentally ill people held by the general public.

In-service training for all categories of nurses should be ensured. Most nurses who passed the three year diploma in general nursing were not exposed to psychiatric nursing and they form the majority of all nurses employed in the public sector. Again in this case, the content of the in-service programme should address the stigmatising factors.

The orientation programme for newly employed nurses should allow them to be in a unit for mentally ill people so as to help them adjust. This will help them overcome their irrational beliefs concerning mentally ill people.

Research should be repeated in a more broadly based sample of nurses. The instrument used in this study should be further evaluated for validity and reliability. Further investigations should be done to dissipate attitudes identified among nurses.

\section{REFERENCES}

Ajzen I.\& Fishbein M.(1980) Understanding Attitudes and Predicting Social Behaviour. Prentice-Hall, London.

Burns, N. \& Groves, S. K. (1993). The Practice of Nursing Research: Conduct, Critique, \& Utilization. Philadelphia : W. B. Saunders Company.
Chinnayya H.P., Chandrashekar C.R., Moily S., Raghuram P.A.Subramanya K.R., Shanmugham V. \& Uduykumar G.S.(1990).Training primary health care workers in mental health care. International Journal of Social Psychiatry 36(4), 300-307.

Clarke L.(1989). The effects of training and social orientation on attitudes towards psychiatric treatment. Journal ofAdvanced Nursing, 14, 485-493.

Hiday V.A.(1983). Are lawyers enemies of psychiatrists: Asurvey of civil commitment council and judges. American Joumal of Psychiatry, 17. $37-40$.

Hornby A.S.(1984). Oxford Student's Dictionary of CurrentEnglish. Oxford University Press, England.

Jaffe Y, Maoz B.\& Avram L.(1979). Mental hospital experiences, classroom instruction and change in conceptions andattitudes towards mental illness. British Journal of MedicalPsychology, 52, 253-258.

Kikby, R.J. \& James, A. (1979). Attitudes of medical practitioners to mental illness. Australian and New Zealand Joumal of Psychiatry 13, 165-168.

Landeen, J., Byrne, C. \& Brown, B. (1992). Journal keeping as an educational strategy in teaching psychiatric nursing. Joumal of Advanced Nursing 17, 347-355.

MacDonald D.M.(1988). Psychiatric services in general hospitals: Rational and irrational considerations. General Hospital Psychiatry, 10, 352-359.

Mack D.E.\& Tosan G.(1980). The effects of ethnicity and education on attitudes towards mental illness in
Southem Nigeria. Intemational Joumal of Social Psychiatry, 26(2), 101-107

Olade R.A.(1983). Attitudes towards mental illness: Effects of integration of mental health concepts into a post-basic nursing degree programme. Journal of Advanced Nursing, 8,83-93.

Taylor S.M., Dear M.J.\& Hall G.B.(1979). Artitude towards the mentally ill and reactions to mental health facilities. Social Science and Medicine, 13D, 281-290.

Uys L.R., Daneel, M.H., Oliver, S.J., Du Pisani, E., Du Toit, J.B., Levine, A \& Strydom, L. (1986) Perception of health and illness and related practices among the urban black population of Mangaung (Bloemfontein). Curationis, 9(4)

28-33.

Wahl O.F.\& Lefkowits J.Y.(1989). Impact of television film on attitudes towards mental illness. American Journal of Community Psychology, 17(4), 512-527.

Thandisizwe Redford Mavundla
M.Cur. (Nursing),RN.
Lecturer:Department of Nursing Science
University of Transkei
Leana R. Uys
D.Soc.Sc. (Nursing Science),RN.
Professor: Head Department of Nursing
University of Natal, DURBAN

